\title{
Viewpoints
}

\section{Sculpting Dendritic Spines during Initiation and Maintenance of Neuropathic Pain}

\author{
${ }^{D}$ Harrison J. Stratton ${ }^{1}$ and ${ }^{\circledR}$ Rajesh Khanna ${ }^{1,2,3,4}$ \\ ${ }^{1}$ Department of Pharmacology, College of Medicine, University of Arizona, Tucson, Arizona $85724,{ }^{2}$ Center for Innovation in Brain Sciences, \\ University of Arizona, Tucson, Arizona 85721, ${ }^{3}$ BIO5 Institute, University of Arizona, Tucson, Arizona 85719, and ${ }^{4}$ Department of Anesthesiology, \\ College of Medicine, University of Arizona, Tucson, Arizona 85724
}

Accumulating evidence has established a firm role for synaptic plasticity in the pathogenesis of neuropathic pain. Recent advances have highlighted the importance of dendritic spine remodeling in driving synaptic plasticity within the CNS. Identifying the molecular players underlying neuropathic pain induced structural and functional maladaptation is therefore critical to understanding its pathophysiology. This process of dynamic reorganization happens in unique phases that have diverse pathologic underpinnings in the initiation and maintenance of neuropathic pain. Recent evidence suggests that pharmacological targeting of specific proteins during distinct phases of neuropathic pain development produces enhanced antinociception. These findings outline a potential new paradigm for targeted treatment and the development of novel therapies for neuropathic pain. We present a concise review of the role of dendritic spines in neuropathic pain and outline the potential for modulation of spine dynamics by targeting two proteins, srGAP3 and Rac1, critically involved in the regulation of the actin cytoskeleton.

\section{Introduction}

Neuropathic pain arises from a lesion or disease of the somatosensory system and is notoriously difficult to treat (Jensen et al., 2011; Alles and Smith, 2018). Neuropathic pain is perplexing because it tends to last far beyond the time of injury and, can become lifelong, as is seen with chemotherapy-induced peripheral neuropathy. This persistent state suggests involvement of underlying mechanisms analogous to those involved in learning and memory, since learned behaviors and memories also persist over a lifetime.

A defining feature of neuropathic pain is the development of central sensitization, which is a heightened response of CNS neurons to previously innocuous stimuli. This suggests the involvement of structural and functional plasticity (Sandkühler, 2007). Primary changes associated with synaptic plasticity include the formation of new dendritic spines and changes to the shape of existing spines on postsynaptic neurons following coordinated and synchronous presynaptic activity (Matsuzaki et al., 2004). These protrusions are functional computational structures that separate and concentrate proteins and ionic gradients to compartmentalize signaling

\footnotetext{
Received June 30, 2020; revised July 31, 2020; accepted Aug. 21, 2020.

Author contributions: H.J.S. and R.K. wrote the paper.

R.K. is the cofounder of Regulonix LLC, a company developing nonopioid drugs for chronic pain. In addition, R.K. has Patents US10287334 and US10441586 issued to Regulonix LLC. The remaining author declares no competing financial interests.

This work was supported by National Institutes of Health Awards R01NS09877202 and R01DA04285202 to R.K. We thank all of those whose work has contributed to the knowledge reviewed here as well as the work

of those not mentioned. Figures were created with BioRender.com.

Correspondence should be addressed to Rajesh Khanna at rkhanna@arizona.edu.

https://doi.org/10.1523/JNEUROSCI.1664-20.2020

Copyright $\odot 2020$ the authors
}

(Tan et al., 2009). Dendritic spines change in response to repeated neuronal firing and are essential for information storage within a neuron. Consequently, they have been implicated in the development of chronic neuropathic pain, and the proteins regulating their formation and maintenance are potential targets of novel pain therapeutics (Benson et al., 2020; Z. Chen et al., 2020). In this review, we discuss dendritic spines and their dysregulation in neuropathic pain states. We focus on two proteins critically involved in distinct stages of spine development, Slit-Robo GTPase-activating protein (srGAP3) and Ras-Related C3 botulinum toxin substrate 1 (Rac1), with a discussion of recent evidence supporting their involvement in pain pathways. Finally, we discuss future directions for investigating how srGAP3 and Rac1 can be targeted for the relief of neuropathic pain.

\section{Dendritic spine dynamics and neuronal plasticity}

The dynamic reorganization of synapses permits activity-dependent storage of information within neuronal membranes (Wefelmeyer et al., 2016). An example of this is the neuronal postsynaptic membrane, a highly specialized computational surface exhibiting a complex morphology that changes in response to sustained and coordinated synaptic activity (Chklovskii, 2004; Anthony and Karel, 2009). Specifically, dendritic spines display robust dynamic behavior, transforming between immature and mature states in response to activity (Segal, 2017). These spines are the primary sites of excitatory synaptic transmission in the CNS and therefore serve as critical interfaces for sculpting neuronal excitability (McKinney, 2010). In addition to neurons, astrocytes play an important role in the maintenance of synaptic structures by regulating levels of extracellular potassium, glutamate, and water. Astrocytes in the rodent brain can envelope as 
many as 140,000 synapses and contact between 300 to 600 dendrites (Ji et al., 2019). Additionally, astrocytes have been shown to play a pivotal role in pruning synaptic inputs to dendritic spines during development of thalamocortical networks (Risher et al., 2014).

\section{Spine structure}

Dendritic spines play an indispensable role in learning and memory; and their shape, distribution, and density positively correlate with increased input (Yang et al., 2014; González-Tapia et al., 2020). The molecular composition of dendritic spines is a veritable cytoplasmic circus, with a broad array of players acting in precise spatial and temporal coordination (Murakoshi and Yasuda, 2012). The distal surface of the dendritic spine houses the postsynaptic density (PSD), a region containing high levels of neurotransmitter receptors and other scaffolding/signaling proteins stabilized through connections with filamentous actin (Factin) (McKinney, 2010). The ionotropic glutamate receptors AMPA and NMDA mediate excitatory neurotransmission and are the primary neurotransmitter receptors within the PSD of dendritic spines (Takumi et al., 1999; Hayashi et al., 2000). These receptors are anchored to the membrane through interactions with PSD 95 (PSD-95), which bind neuroligins, a class of postsynaptic cell adhesion molecule that binds presynaptic neurexins and forms a membrane-located anchoring complex (Wefelmeyer et al., 2016) (Fig. 1).

Classification of spines has largely relied on shape, with four widely recognized categories: filopodial, thin, stubby, and mushroom (Hering and Sheng, 2001). The spine neck originates at the primary dendritic branch and connects to a rounded compartment that constitutes the head, which serves as the principal site of contact with presynaptic boutons. Filopodial spines are a nascent category of spine that has a role in synaptogenesis by extending from the dendritic shaft in search of a synaptic partner. These spines are fleeting, but can stabilize on contact with a presynaptic counterpart, which forms the beginning of a synaptic connection (Eom et al., 2003). Thin spines are immature and have a long thin neck with a small head (PorteraCailliau et al., 2003). This category of spines has rapid turnover, but can stabilize with consistent activity. Because of the higher turnover, these spines are thought to be predominantly involved in rapid responses to changes in presynaptic input and are able to capture changes in activity over a shorter time scale. Mushroom spines have a large bulbous head with a short and narrow neck and are considered mature (Berry and Nedivi, 2017). This category of spine is significantly more stable with a lower turnover and is proposed to serve as a structural correlate of memory by enabling long-term storage of past activity (Zuo et al., 2005). Stubby spines have a large bulbous head and a short fat neck and are also considered mature. The spine life cycle begins with immature filopodial spines and progresses to mature mushroom spines, which correlates with the level of synaptic activity (Hlushchenko et al., 2016). Therefore, dendritic spine structure serves as a proxy for the level of local synaptic activity, and changes in spine structure can be used as an indicator of past synaptic activity (Park et al., 2019).

Actin, a cytoskeletal element heavily concentrated in the distal portion, as well as the neck, of dendritic spines, serves as a primary structural scaffold and gives spines their distinctive shape (Cingolani and Goda, 2008; Borovac et al., 2018). The regulation of cytoskeletal actin within dendritic spines is essential for progression from immature to mature states and is largely achieved

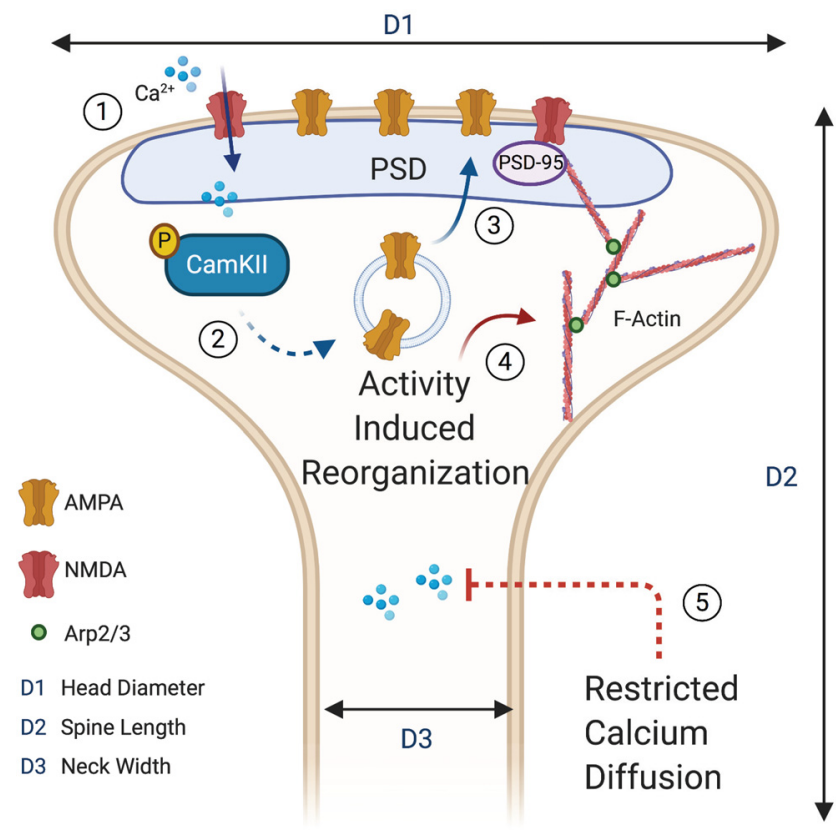

Figure 1. Structural and functional dendritic spine adaptation. Dendritic spines are dynamic structures that change their shape and membrane composition following synchronous and coordinated presynaptic signaling. (1) Sustained postsynaptic depolarization causes removal of the magnesium blockade from N-methyl-D-aspartate (NMDA) receptors, which allows increased intracellular calcium concentrations. (2) Increased intracellular calcium induces phosphorylation (P) of CaMKII, which increases its activity and drives postsynaptic events leading to synaptic potentiation. (3) One of the postsynaptic events triggered by CaMKII activation is the insertion of additional $\alpha$-amino-3-hydroxy-5-methyl-4-isoxazolepropionic (AMPA) receptors into the head of the dendritic spine in the region of the PSD. (4) High levels of postsynaptic activity trigger polymerization of soluble $\mathrm{G}$-actin into filamentous F-actin, which form branching networks with the actin regulating protein 2/3 (Arp2/3) serving as a nucleation site. Highly branched actin networks are found in mature dendritic spines. (5) The thinner neck found in mushroom-shaped spines restricts the diffusion of calcium into the dendritic shaft and allows for locally elevated levels to be maintained. Three spatial dimensions, head diameter (D1), spine length (D2), and neck width (D3) are primarily used to classify spines into defined categories. Spine with large heads tend to have a greater volume, larger PSD, more glutamatergic receptors, and greater signaling efficacy.

through activity of the Wiskott-Aldrich syndrome protein-family verprolin homologous protein (WAVE) regulatory complex (WRC) (Y. Kim et al., 2006). When activated, this complex initiates binding of actin-related protein 2/3 (Arp2/3) to F-actin and promotes polymerization of soluble actin (G-actin) into newly branched filaments (Y. Kim et al., 2006; Z. Chen et al., 2010). Actin regulatory proteins, such as WAVE1, are controlled by small Rho GTPases, which switch between active and inactive states through hydrolysis of GTP (Y. Kim et al., 2006). An integral regulatory protein involved in this process is Rac1, which is a primary member of the Rho family of small $(\sim 21 \mathrm{kDa})$ GTPases (Marston et al., 2019). Rac1, cdc42, and RhoA are the most well-studied members of the Rho small GTPase family (Wong et al., 2001; Tolias et al., 2007; Payapilly and Malliri, 2018; Paskus et al., 2020). In its active state, Racl is translocated to the plasma membrane and mediates a wide variety of cellular processes, including neurite outgrowth, and maintenance of mature dendritic spines (Gonzalez-Billault et al., 2012; Raemaekers et al., 2012; Li et al., 2019) (see Fig. 3). Modification of the C-terminal domain of Racl occurs in the cytoplasm by Geranylgeranyl Transferase 1 (GGT-1), which is the first step in allowing membrane targeting of Racl and precedes its involvement in dendritic spine reorganization (Seabra, 1998; Bustelo et al., 2012; Kalpachidou et al., 2019). 
The Rho GTPases are in turn regulated by proteins that mediate the transition between active, GTP bound, and inactive, GDP bound states (Bustelo et al., 2012). Activity is promoted by guanine nucleotide exchange factors (GEFs), which exchange GDP for GTP, and is inhibited by Rho GAPs (Jaudon et al., 2015). In addition, Rho GTPases can be sequestered in the cytoplasm by binding to guanine nucleotide dissociation inhibitors (GDIs), which prevent GAPs and GEFs from exerting their regulatory effects. Through this complex network of protein interactions, cytoskeletal actin networks respond rapidly to external stimuli, such as neurotrophic factors, activation of metabotropic glutamate receptors, and other signaling proteins (Hedrick et al., 2016).

\section{Spine function}

Recent advances in fluorescent microscopy have allowed in vivo observation of dendritic spine dynamics in real time (Marston et al., 2019). These studies dramatically improved our understanding of these neuronal structures. One key function attributable to dendritic spines is the segregation and compartmentalization of synaptic signals. Calcium imaging revealed that the thin neck of mushroom-shaped spines prevents cytoplasmic calcium from diffusing into the dendritic shaft (Hering and Sheng, 2001). This has significant implications for the regulation of calcium-dependent signaling cascades. One such signaling pathway involves activation of CaMKII, a calcium-calmodulin kinase that has been extensively studied in the context of synaptic plasticity, which phosphorylates AMPA receptors that are then trafficked to the membrane following sustained activity (Fig. 1) (Hill and Zito, 2013). As a regulator of synaptic plasticity, the CaMKII pathway has been implicated in the development of neuropathic pain, and levels of CaMKII are increased in the spinal cord after spinal nerve ligation, which is a model of neuropathic pain. Blocking the activity of CaMKII using the compound KN93 dose-dependently reversed nerve injury-induced mechanical allodynia and thermal hyperalgesia while also decreasing levels of CaMKII in the spinal cord (Y. Chen et al., 2009). This evidence directly suggests that CaMKII activity is relevant to neuropathic pain (Kawano et al., 2009).

Functionally, increased numbers of AMPA receptors in the postsynaptic membrane, such as following CaMKII activation, permit larger membrane depolarizations in response to presynaptic transmitter release and are a critical component of synaptic plasticity (Nguyen et al., 2012). The size of the dendritic spine postsynaptic density roughly correlates with the number of AMPA and NMDA receptors, which directly connect structure of spines to their function. In addition, the size of the spine neck reflects the level of restriction imposed on calcium ion diffusion and again links spine structure to function. For example, stubby spines and mushroom spines are both considered mature with large bulbous heads that contain larger numbers of AMPA and NMDA receptors (Hering and Sheng, 2001). The primary difference between these classes of spines is reflected in the neck diameter. In stubby spines, with a wide neck, there is little restriction of calcium diffusion and ions can readily diffuse into the dendritic shaft, which limits the duration of elevated calcium transients at the synapse. Alternatively, mushroom spines have a narrow neck, which restricts the diffusion of calcium to the shaft and increases the duration of local calcium transients at the synapse (Hayashi and Majewska, 2005).

\section{Dendritic spine dysgenesis in neuropathic pain}

Nociceptive sensitization is present in organisms across the animal kingdom from Aplysia californica to Homo sapiens, and it is a fundamental response to injury (Woolf and Walters, 1991). In the field of pain research, a consensus has emerged that aberrant neuronal plasticity within the CNS is a primary mechanism underlying the transition from acute to chronic neuropathic pain (Tan, 2015). Acute neuropathic pain, which occurs over shorter durations, does not persist for long enough to activate the physiological plasticity mechanisms that manifest in chronic conditions. According to this model, repetitive activity in pain circuits, induced by injury, disease, or other factors, triggers a maladaptive response involving synaptic plasticity, termed central sensitization. This process is characterized by strengthening of synaptic connections in pain processing regions, such as the dorsal horn of the spinal cord. This synaptic strengthening is thought to involve many of the same molecular mechanisms that underlie long term potentiation (LTP), which are thought to form the functional and structural foundation of learning and memory (Matsuzaki et al., 2004; Yang and Zhou, 2009; Hill and Zito, 2013). These mechanisms, including activation of CaMKII, upregulation of AMPA receptors, and changes to gene transcription, are also proposed to underlie the transition from acute to chronic neuropathic pain (Melemedjian et al., 2013). This similarity in signaling mechanisms opens the possibility that the components involved in dendritic spine formation in memory are also involved in shaping spines in neuropathic pain, and may therefore be targeted to treat pain (Tan and Waxman, 2015).

\section{Pan-pain dendritic spine dysgenesis}

Aberrant dendritic spine formation has been observed in several preclinical neuropathic pain models, including diabetic peripheral neuropathy, spinal cord injury (SCI), peripheral nerve injury, cutaneous burn, and chemotherapy-induced peripheral neuropathy (Tan et al., 2011, 2012, 2013; Cao et al., 2017; Z. Chen et al., 2020) (Table 1). Each of these models displays a similar pattern of spine changes, including a greater number of stable/mature mushroom-shaped spines, an increase in overall spine density, and a redistribution of spines toward the dendritic branches closer to the soma (Fig. 2). This translates into greater signaling efficacy that profoundly increases the activity of nociceptive neurons (Zhao et al., 2016). Since this pattern is consistent across pain models, it constitutes a structural signature, a proxy indicator of neuropathic pain.

This phenotype of enhanced excitability caused by dendritic spine dysgenesis was initially investigated using computational modeling. These simulations indicated that increased numbers of mushroom-shaped spines closer to the soma induced a hyperexcitable state conducive to heightened transmission of noxious stimuli (Tan et al., 2009). Together, these findings provide experimental and theoretical foundations supporting the notion that dendritic dysgenesis is fundamental for neuropathic pain.

\section{Dendritic spine dysgenesis in spinal cord}

Recent advances in fluorescent microscopy have permitted unprecedented investigations of real-time dendritic spine formation in live tissues and whole organisms (Hayashi-Takagi et al., 2015). This approach was recently used by Benson et al. (2020) to follow the evolution of dendritic spines in the dorsal horn of the spinal cord before and after spared nerve injury (SNI). The authors used Thy1-YFP mice to visualize spines of lamina II neurons in the spinal dorsal horn after implantation of a small window above the spine. This technique has been applied in other brain regions, but it is revolutionary for studying the spinal cord because it allows direct visualization of dendritic spines in the same animal over time. The outcome of this work validated 
Table 1. Key references indicating the importance of srGAP3/Rac1 in dendritic spines

\begin{tabular}{|c|c|c|c|}
\hline Reference & Pain model & $\begin{array}{l}\text { Mechanism/signaling } \\
\text { pathway }\end{array}$ & Key findings \\
\hline Tan et al. (2013) & $\begin{array}{l}\text { Partial thickness } \\
\text { burn injury }\end{array}$ & $\begin{array}{l}\text { Rac1 (NSC23766) } \\
\text { WDR neurons in lamina } \\
\text { IV-V }\end{array}$ & $\begin{array}{l}\text { Rats with burn injury exhibited reduced mechanical withdrawal thresholds and hyperexcitable WDR neu- } \\
\text { rons of the spinal dorsal horn. Dendritic spine dysgenesis was observed on ipsilateral WDR neurons. } \\
\text { Application of NSC23766 decreased mechanical allodynia, WDR neuron hyperexcitability, and aberrant } \\
\text { spine dysgenesis. }\end{array}$ \\
\hline Benson et al. (2020) & SNI & $\begin{array}{l}\text { Dendritic spine dysgenesis } \\
\text { in lamina II }\end{array}$ & $\begin{array}{l}\text { Used in vivo two photon imaging to follow dendritic spine formation before and after SNI-induced neu- } \\
\text { ropathic pain neuropathic pain using within subject control. Identified key trends in spine dysgenesis } \\
\text { following neuropathic pain, suggesting a common maladaptive response in painful neuropathy. } \\
\text { Specifically, increased numbers of mushroom spines were observed on dendritic shafts closer to the } \\
\text { soma and these changes corresponded with enhanced behavioral responses associated with pain. }\end{array}$ \\
\hline Cao et al. (2017) & $\begin{array}{l}\text { Thoracic spinal con- } \\
\text { tusion injury (SCl) }\end{array}$ & $\begin{array}{l}\text { Rac1 (NSC23766) } \\
\text { Superficial lamina II } \\
\quad \text { neurons }\end{array}$ & $\begin{array}{l}\text { Structural analysis of spinal cord slices obtained from a previous study investigating WDR neurons using } \\
\text { Golgi staining to observe spine structure. Slices were analyzed with a focus on superficial neurons of } \\
\text { lamina II. Thin spine density decreased, and mushroom spine density increased with overall spine } \\
\text { density remaining constant. Treatment with Rac1 inhibitor reversed these changes to dendritic spine } \\
\text { profiles in lamina II neurons of the superficial dorsal horn. Structural changes were most significantly } \\
\text { noted on dendritic branches within } 150 \mu \mathrm{m} \text { of the soma. }\end{array}$ \\
\hline Z. Chen et al. (2020) & PIPN & $\begin{array}{l}\text { srGAP3 (siRNA) and Rac1 } \\
\text { (NSC23766) } \\
\text { Superficial lamina II } \\
\text { neurons }\end{array}$ & $\begin{array}{l}\text { The emergence of dendritic spine dysgenesis can be ameliorated with inhibition of srGAP3 using an } \\
\text { siRNA-based approach when this intervention is applied during the initiation phase of neuropathic } \\
\text { pain. Blockade of Rac1 signaling is most effective when applied in the maintenance phase of neuro- } \\
\text { pathic pain, }>10 \mathrm{~d} \text { following cessation of paclitaxel treatment. When combined and applied during } \\
\text { their respective treatment window, the effects of srGAP3 and Rac1 inhibition are compounded, result- } \\
\text { ing in near-complete reversal of mechanical allodynia. This behavioral outcome is mirrored in the } \\
\text { changes in dendritic spines observed in lamina II of the spinal dorsal horn where the combined inter- } \\
\text { vention maximally reduces dendritic spine dysgenesis. }\end{array}$ \\
\hline Tan et al. (2012) & $\begin{array}{l}\text { Streptozotocin- } \\
\text { induced diabetic } \\
\text { peripheral } \\
\text { neuropathy }\end{array}$ & $\begin{array}{l}\text { Rac1 (NSC23766) } \\
\text { WDR neurons of lamina } \\
\text { IV-V }\end{array}$ & $\begin{array}{l}\text { Diabetes-induced malformation of dendritic spines on WDR neurons in lamina IV-V of STZ-treated rats. } \\
\text { This treatment altered the shape and distribution of spines on WDR neurons with an accompanying } \\
\text { increase in excitability that was associated with the onset of mechanical hypersensitivity at } 4 \text { weeks } \\
\text { following induction with STZ. Treatment with NSC23766 reduced spontaneous firing, attenuated pe- } \\
\text { ripheral hypersensitivity, and decrease the presence of malformed spines on WDR neurons. }\end{array}$ \\
\hline $\begin{array}{l}\text { Tan et al. (2008); } \\
\text { Zhao et al. (2016) }\end{array}$ & Thoracic (T9) SCl & $\begin{array}{l}\text { Rac1 (NSC23766) } \\
\text { WDR lamina IV-V neurons }\end{array}$ & $\begin{array}{l}\text { Following } \mathrm{SCl} \text {, rats displayed neuronal hyperexcitability and neuropathic pain that correlated with aber- } \\
\text { rant dendritic spine profiles. WDR neurons displayed enhanced field potential responses to innocuous } \\
\text { stimulation, and rats exhibited tactile and thermal hyperalgesia. Inhibition of Rac1 reduced aberrant } \\
\text { dendritic spine formation and ameliorated } \mathrm{SCl} \text {-induced changes to spine profiles and behavioral } \\
\text { responses. Additionally, intervention with NSC23766 was most effective when it was applied intrathe- } \\
\text { cally more than } 4 \text { weeks following injury, suggesting a temporal window for maximal efficacy. }\end{array}$ \\
\hline Tan et al. (2011) & $\begin{array}{l}\text { Chronic constriction } \\
\text { injury }\end{array}$ & $\begin{array}{l}\text { Rac1 (NSC23766) } \\
\text { WDR lamina IV-V neurons }\end{array}$ & $\begin{array}{l}\text { Increased mushroom-shaped spines that were preferentially formed on dendritic branches closer to the } \\
\text { soma at } 10 \mathrm{~d} \text { after chronic constriction injury. WDR neurons exhibited a hyperexcitable profile meas- } \\
\text { ured using single-unit extracellular recordings in vivo. These neurons also displayed exaggerated } \\
\text { responses to innocuous stimuli when applied to the periphery. Reduced nociceptive thresholds were } \\
\text { observed ipsilateral to the injury site. Following } 3 \mathrm{~d} \text { treatment with NSC23766, spine densities, hyper- } \\
\text { excitability, and behavioral nociceptive thresholds were returned to lower levels, but did not reach } \\
\text { the levels observed in the sham condition. Importantly, treatment reduced the symptoms associated } \\
\text { with mechanical hyperalgesia, but did not influence thermal hyperalgesia responses. }\end{array}$ \\
\hline Patwa et al. (2019) & $\begin{array}{l}\text { Second degree burn } \\
\text { injury (hindpaw) }\end{array}$ & $\begin{array}{l}\text { Pak1 (romidepsin) } \\
\text { Alpha-motor neurons }\end{array}$ & $\begin{array}{l}\text { Alpha-motor neurons innervating the burned skin region, the hindpaw, displayed increased overall den- } \\
\text { sities of dendritic spines and higher numbers of mushroom-shaped dendritic spines that were consid- } \\
\text { ered structurally mature. Following treatment with romidepsin, an FDA-approved Pak1 inhibitor, the } \\
\text { spine profiles of these neurons returned to a near baseline state, and this effect lasted for } 4 \mathrm{~d} \text { follow- } \\
\text { ing cessation of treatment. This suggests that Pak1 is a more durable target for modulating dendritic } \\
\text { spine dysgenesis and extends previous findings to new regions of the spinal cord. }\end{array}$ \\
\hline Guo et al. (2018) & $\begin{array}{l}\text { Second degree burn } \\
\text { injury (hindpaw) }\end{array}$ & $\begin{array}{l}\text { Pak1 (romidepsin) } \\
\text { WDR neurons of lamina } \\
\text { IV-V }\end{array}$ & $\begin{array}{l}\text { Mice exhibited significant spine dysgenesis, tactile and thermal hyperalgesia, and activity-dependent } \\
\text { increases in c-fos expression in neurons of the spinal dorsal horn. Treatment with romidepsin } \\
\text { decreased dendritic spine dysgenesis, rescued pain threshold, and reduced c-fos expression, which } \\
\text { returned to levels associated with pain on cessation of treatment. }\end{array}$ \\
\hline Price et al. (2007) & SNI & Fmr1 K0, FMRP & $\begin{array}{l}\text { Mice lacking FMRP (Fmr1 KO) displayed delayed development of mechanical hypersensitivity following } \\
\text { SNI. Additionally, these mice displayed decreased windup, which is an electrophysiological hallmark } \\
\text { of central sensitization involved in neuropathic pain development and is thought to be reliant on the } \\
\text { LTP. These mice also displayed aberrant mGluR1/5-mediated nociceptor plasticity. This is significant } \\
\text { because FMRP is involved in the formation of dendritic spines; and although spine formation was not } \\
\text { directly measured in this study, the finding still implicates spine-associated proteins in nociceptive } \\
\text { signaling. }\end{array}$ \\
\hline
\end{tabular}

previous findings demonstrating that the formation of mature dendritic spines corresponds with the development of neuropathic pain. Importantly, the authors showed that the maximal formation of mushroom-shaped spines coincided with maximal pain intensity, which strongly suggests a causal relationship. These findings provide validation for the working model suggesting that neuropathic pain induces changes in dendritic spine number and formation, which drives alterations in synaptic 


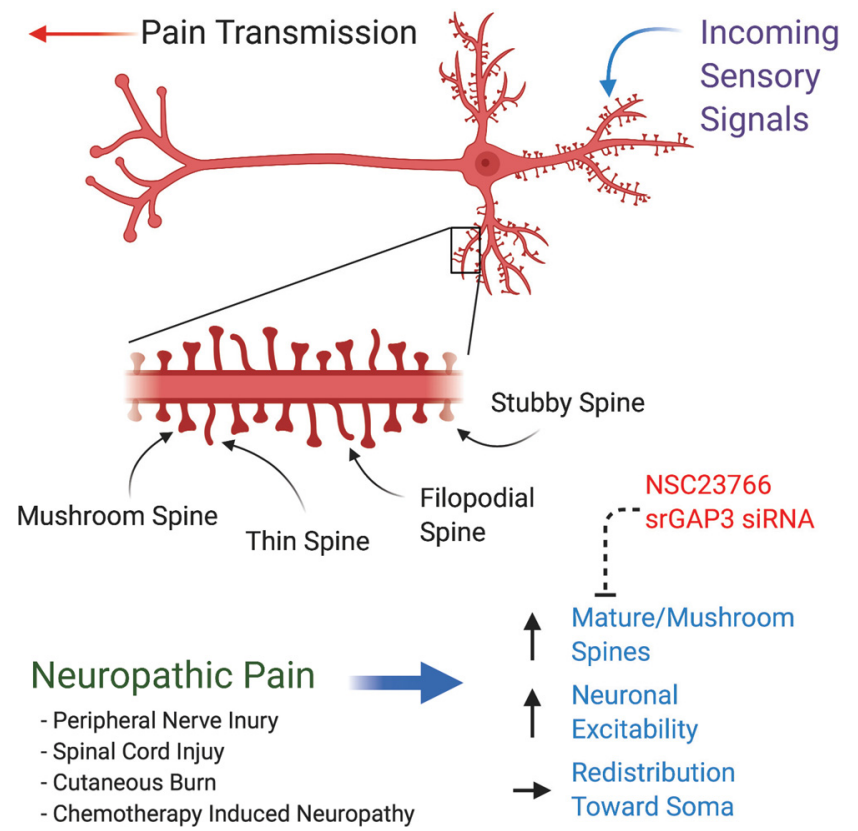

Figure 2. Structural changes to dendritic spines in neuropathic pain. Sensory neurons receive nociceptive input at excitatory dendritic spines located at the distal dendritic branches. Spatial and temporal summation occurs in the soma, and output is transmitted along the axon as an action potential. Dendritic spines are broadly classified into four categories: stubby, mushroom, filopodial, and thin spines. Mushroom spines are mature, stable, and have highly branched actin networks. Filopodial spines are like thin spines, which generally act as a means of sensing new synaptic connections. Thin spines are transient and on sustained synaptic activity can mature into mushroom-shaped spines. Stubby spines are also a mature category with a short but wide neck region that has limited capacity for restriction of calcium diffusion. The spine life cycle begins with immature filopodial spines and progresses to mature mushroom spines, which correlates with the level of synaptic activity. Neuropathic pain results in common changes to the dendritic spine profile of sensory neurons in the dorsal horn of the spinal cord characterized by increased density of mature/mushroom spines, increased neuronal excitability, and a redistribution of spines toward the soma. These changes can be ameliorated by inhibition of Rac1 using intrathecal administration of NSC23766 and blockade of srGAP3 using intrathecal siRNA injection.

efficacy and promotes neuropathic pain (Benson et al., 2020). One limitation of this study, however, was the short duration over which spines were observed, at only $7 \mathrm{~d}$. Further studies investigating the functional as well as structural components of plasticity over longer durations will be essential for extending this work and clearly establishing the link between aberrant synaptic plasticity and the development of chronic neuropathic pain.

\section{Dendritic spines in higher brain regions}

In addition to dendritic spine dysgenesis in the spinal cord, neuropathic pain produces spine changes in higher brain regions, including the hippocampus. Similar to the structural changes in the spinal cord, neuropathic pain after chronic constriction injury induced alterations in dendritic tree morphology as well as altering the type and number of dendritic spines in the mouse hippocampus (Tsai et al., 2009; Tyrtyshnaia and Manzhulo, 2020). This finding suggests that neuropathic pain produces aberrant structural plasticity in diverse neuronal structures involved in the processing of sensory information (Tsai et al., 2009). The dysregulation of spines in the hippocampus might explain the connection between chronic neuropathic pain and the development of anxiety and depression, which are often comorbid in patients with neuropathic pain (Woo, 2010; Golden et al., 2013; Lee et al., 2018; Tyrtyshnaia and Manzhulo, 2020). Acute increases in dendritic spine turnover of primary cortical somatosensory circuits accompany neuropathic pain after peripheral nerve injury (S. K. Kim et al., 2016). These changes to spine dynamics are associated with increased cortical excitability and the emergence of mechanical allodynia. The changes to cortical dendritic spines are regulated by neuronal mechanisms discussed thus far, but are also critically influenced by the activity of local astrocytes. Specifically, release of thrombospondin-1 from cortical astrocytes after nerve injury promotes synaptic rewiring and sustained mechanical allodynia (S. K. Kim et al., 2016). Additionally, astrocytes can control excitatory synaptogenesis and spinogenesis by secreting thrombospondins that interact with the calcium channel subunit a $2 \delta-1$ and promotes postsynaptic activation of Racl (Risher et al., 2018).

In contrast to the changes observed after injury in the studies described above, neurons tend to lose dendritic spines after loss of input, which occurs, for example, after thoracic spinal transection. Ghosh et al. (2012) found that cortical layer 5 neurons lost dendritic spines, and this loss occurred significantly faster in the proximal dendrites than the distal dendrites; the authors postulated that this response was an adaptive mechanism to redistribute neuronal connectivity toward other synaptic partners with intact signaling.

Together, these findings demonstrate that reorganization of postsynaptic dendritic spines is a global phenomenon after disruption of normal signaling and that this reorganization is highly associated with neuropathic pain. The molecular mediators that trigger and regulate this profound structural redistribution of dendritic spines therefore provide excellent candidates for therapeutic targets in the treatment of neuropathic pain.

\section{Rac1 controls spine maturation and neuropathic pain Rac1 control of WAVE1}

The primary mode of Racl control over actin regulatory elements is through its interaction with WAVE1. Upon binding of Rac1, inhibition of WAVE1 is removed, initiating translocation from the cytoplasm to the membrane, which subsequently causes binding of Arp2/3 to F-actin (Eden et al., 2002; Sung et al., 2008) (Fig. 3). Expression of dominant-negative WAVE1 prevents the formation of Rac1-dependent, but not Cdc42-dependent, lamellipodia- and Rac1-dependent neurite extension (Miki et al., 1998; Soderling et al., 2002). Furthermore, recent determination of the WRC structure using cryo-electron microscopy has revealed that Racl does not bind solely to the traditional site defined by biochemical and mutagenesis studies. Instead, WRC was shown to bind two Rac1 molecules: one at the traditional binding site and another at a higher affinity site on the opposite end of the Sral component of the WRC (Schaks et al., 2018). This suggests that the WRC is able to sense the concentration of Racl and is consequently able to finely control the polymerization of actin to govern cytoskeleton formation (B. Chen et al., 2017). These molecular regulators of Racl could provide novel avenues for controlling the activity of Racl and subsequently reversing aberrant dendritic spine formation observed in neuropathic pain.

Evidence for role of Rac1 in pain

Over the past decade, a large body of work has emerged supporting the role of this small protein in the maintenance of dendritic spines associated with neuropathic pain. Evidence has emerged suggesting that temporal modulation of Racl is critical for spine maturation, especially in neuropathic pain states (Tashiro and Yuste, 2004). Using a rat model of SCI, Zhao et al. (2016) showed 


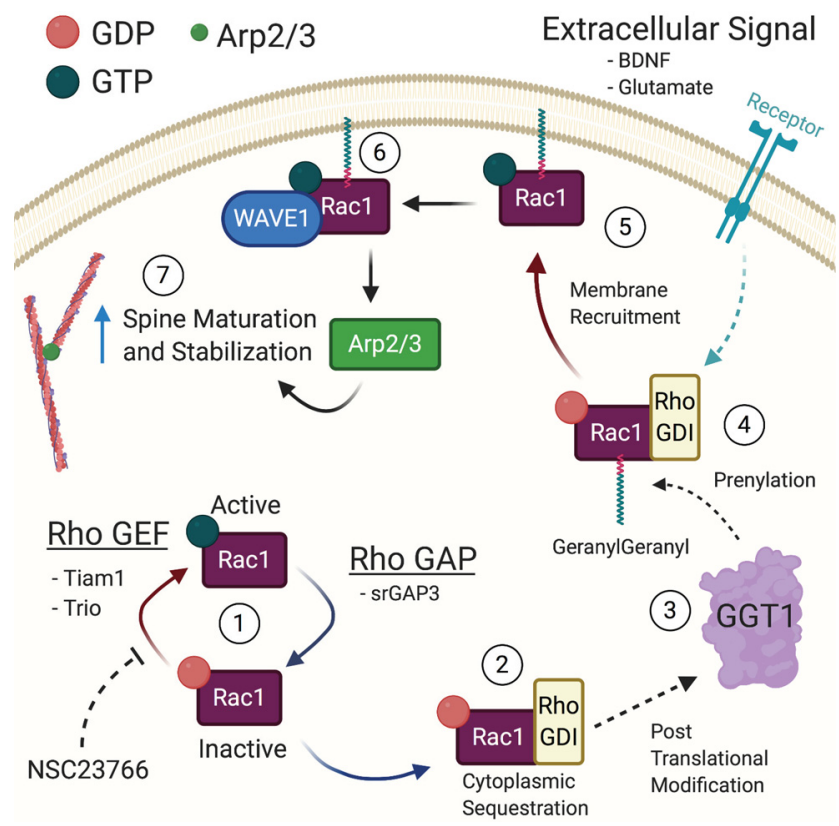

Figure 3. Rac1 signaling cycle in dendritic spines. The spatial and temporal activity of Rac1 is tightly controlled through a network of signaling interactions and post-translational modifications. (1) The primary regulators of Rac1 are the GEFs, which activate Rac1 by exchanging GDP for GTP, and the GAPs, which inactivate Rac1 by accelerating the hydrolysis of GTP. The compound NSC23766 specifically inhibits Rac1 activity by blocking the GEFs Tiam1 and Trio. (2) In its inactive state, Rho GDls act to sequester Rac1 in the nucleus and protect it from proteolytic degradation. (3) The enzyme GeranylGeranyl Transferase 1 (GGT1) post-translationally modifies Rac1 through the addition of a geranylgeranyl lipid group. (4) Following prenylation, Rac1 is ready to be activated. (5) Upon activation of an upstream effector, such as receptor tyrosine kinase or mGluRs, the prenylated Rac1 loses the Rho GDI and has GDP exchanged for GTP, resulting in activation. (6) Activated Rac1 then binds to WAVE1 at the membrane and causes activation of Arp2/3, which can then bind to already established F-actin. (7) Binding of Arp2/3 increases the number of branched actin filaments and drives the dendritic spine into a more stable configuration. Rho GEF, Rho guanine nucleotide exchange factor; Rho GAP, Rho GTPase activating protein; Rho GDI, Rho guanine nucleotide dissociation inhibitor.

that Rac1 is involved in the formation of mature dendritic spines and the development of SCI-induced neuropathic pain (see also Tan et al., 2008). Early inhibition of Rac1 activity through intrathecal administration of the Rac1-specific inhibitor NSC23766, which specifically blocks the Rho guanine nucleotide exchange factors Tiam 1 and Trio, produced mild antinociception and minimal disruption to spines of lamina IV-V wide dynamic range (WDR) neurons. WDR neurons are readily sensitized by intense noxious stimuli and exhibit a frequency-dependent increase in neuronal excitability in response to repeated input from afferent C-fibers (Guan et al., 2006). These neurons are convergent sites for incoming somatosensory, as well as nociceptive signals, and are therefore important in processing painrelated information. Interestingly, delayed intervention with NSC23766, at 4 weeks after injury, produced significant antinociception and was accompanied by a less-mature dendritic spine profile. In addition to the structural findings, the authors reported changes to electrophysiological properties of WDR neurons after SCI and NSC23766 treatment (Zhao et al., 2016). Specifically, the number of spikes recorded from nociceptive WDR neurons was increased after SCI, and this pattern was subsequently abolished by late treatment with NSC23766 (Cao et al., 2017).

Neurons of the superficial layers (I/II) of the spinal cord primarily receive peripheral afferent input from $\mathrm{A} \delta, \mathrm{C} / \mathrm{A} \delta$ peptidergic, and $\mathrm{C}$ nonpedtidergic nociceptive fibers, which makes this region essential for transmission and processing of pain signals (Todd, 2010). Similar to the findings in WDR neurons, dendritic spines in the superficial layers of the spinal dorsal horn also undergo dendritic spine remodeling after SCI, and this remodeling is sensitive to attenuation with NSC23766. This suggests that neuropathic pain produces a characteristic pattern of dendritic spines dysgenesis in two different regions of the spinal dorsal horn. These findings support the role of Racl in dendritic spine maturation associated with neuropathic pain and point to a key window of time later in the development of neuropathic pain where inhibition of Rac1 might be most efficacious.

While NSC23766 has demonstrated efficacy in reducing the mechanical hypersensitivity component of neuropathic pain, it is ineffective in reducing the thermal component in all models, except for SCI (Tan et al., 2008). This implies a unique pathophysiological mechanism underlying the development of thermal hypersensitivity independent of Racl and highlights gaps in our understanding of the molecular mechanisms by which Racl inhibition mediates its beneficial effects. Currently, it is believed that the effects of NSC23766 are mediated through inhibition of GEFs (Tiam1, Trio) that activate Rac1, but spare the downstream effector of Rac1: p21-associated kinase (Pak1). Interestingly, inhibition of Pak1 activity with the FDA-approved inhibitor romidepsin significantly attenuated aberrant dendritic spine formation and reduced thermal hypersensitivity in a burn-injury model of neuropathic pain (Guo et al., 2018; Patwa et al., 2019). This finding highlights the broad array of protein networks that Racl is a part of, thus complicating potential interventions. Further studies are necessary to understand and target the exact molecular pathways involved in analgesia mediated by Rac1 inhibition.

Evidence for the involvement of Racl in dendritic spine dysgenesis extends beyond a single pain model and includes multiple different modalities of neuropathic pain, suggesting a pan-pain role for Rac1 (Tan et al., 2008, 2011, 2013). Beyond sensory neurons, Rac1 has also been implicated in dendritic spine dysgenesis in $\alpha$ motor neurons of the spinal cord following SCI. These neurons reflect a similar dysgenic profile to that observed in spinal sensory neurons following injury and point to a conserved mechanism of dendritic remodeling sensitive to Rac1 modulation in diverse regions of the CNS (Bandaru et al., 2015; Pennucci et al., 2019). The widespread involvement of Racl in dendritic spine dysgenesis associated with chronic pain illustrates the potential for Racl to serve as a biomarker for dendritic spine malformation in neuropathic pain (Zhao et al., 2016).

\section{Connection to fragile $X$ ?}

Translation of these findings regarding Racl signaling to human populations has not been explored to date. However, one opportunity exists among the Fragile $\mathrm{X}$ mental retardation syndromes, which are the most frequently occurring genetic forms of intellectual disability and have been linked to the development of autism spectrum disorders in humans (Pyronneau et al., 2017). Mice lacking the gene Fmrl, which codes for Fragile X Mental Retardation Protein (FMRP), exhibit significantly impaired hippocampal LTP and malformed dendritic spines (L. Y. Chen et al., 2010). This dysfunction has been linked to Racl signaling, supporting the notion that Racl is a crucial regulator of synaptic transmission and dendritic spine plasticity (L. Y. Chen et al., 2010; Bongmba et al., 2011). Notably, FMRP is expressed in nociceptive neurons of the superficial spinal dorsal horn, where it plays a role in nociceptive plasticity. Mice deficient in Fmr1 have reduced metabotropic glutamate receptor (mGluR) 1/5- 
mediated nociceptor plasticity, display delayed development of mechanical allodynia after nerve injury, and exhibit reduced windup, a core electrophysiological feature associated with central sensitization. These findings demonstrate that Fmrl is essential for the development of central sensitization and nerve injury-induced neuropathic pain (Price et al., 2007). Interestingly, neuropathy is a common complaint among patients with fragile$\mathrm{X}$-associated tremor ataxia syndrome, which is a late-onset disorder in those that carry an expanded allele of FMR1 (Hagerman et al., 2007; Rodriguez-Revenga et al., 2009). This suggests that there is potentially a link between the enhanced neuropathic pain observed in murine FMR1 KO studies and clinical populations, which highlights the translational potential of these findings.

Moreover, Fmr1 KO mice exhibit increased pathologic densities of filopodial/immature dendritic spines and increased Rac1-PAK1 signaling activity in the somatosensory cortex, consistent with involvement of Rac1 in the formation of Fmr1-associated synaptic defects. Rac1-PAK1 signaling promotes the phosphorylation and thus inactivation of cofilin and overexpression of constitutively active cofilin reduced aberrant spine morphology and density in the somatosensory cortex (Pyronneau et al., 2017). Additionally, PAK1 inhibition was able to correct impaired cofilin signaling, glutamatergic tone, and sensory processing in Fmr1 KO mice in vivo. Together, these findings suggest that Rac1-PAK-cofilin signaling is associated with the dendritic spine defects and synaptic dysfunction observed in Fragile X Syndrome (Pyronneau et al., 2017). Extrapolating from these results, it is possible that the Rac1-PAK-cofilin signaling network also controls dendritic spine maturation in the dorsal horn of the spinal cord and regulates the development of neuropathic pain. Collectively, these findings indicate that Racl is an important mediator of synaptic plasticity through its modulation of dendritic spine maturation; thus, this mechanism could serve as a foundation for the extension of preclinical studies into clinically translatable therapies targeting the interaction between FMRP and Rac1.

\section{Other Rac1 interaction partners}

Expanding our knowledge of Rac1 signaling networks, a recent study identified the Nrp1/PlxnA4/Rac1/Farp2 cascade downstream of Semaphorin 3A (Sema3A) as a novel player in dendritic spine formation (Danelon et al., 2020). Sema3A is a secreted protein that binds to a receptor complex containing neuropilin-1 and a plexinA coreceptor, which serves to direct dendritic growth and acts as a chemorepulsant factor responsible for guiding axonal growth cones to their postsynaptic targets (Goshima et al., 2016). These findings show that the Sema3A pathway acts via a KRK motif on the PlxnA4 receptor that activates Farp2, which is a RhoGEF, and Racl to control dendrite morphogenesis in layer 5 cortical neurons (He et al., 2013). This study conclusively demonstrated a dendrite-specific signaling pathway, including PlxnA4, Farp2, and Rac1, which adds to the already well-established idea that Racl is a crucial mediator of dendrite patterning and spine formation (Danelon et al., 2020).

Another link between Racl and the Sema3A signaling cascade is found in the interaction between collapsin response mediator protein 2 (CRMP2) and the Sra-1/WAVE1 complex. The cytosolic protein CRMP2 mediates transport of the Sra-1/WAVE1 complex, where, as noted above, it regulates the formation and remodeling of dendritic spines. The involvement of CRMP2 in neuropathic pain and in synaptic signaling has been well established, further highlighting the connection between the regulation of dendritic spine growth and the development of neuropathic pain. Given that both Rac1 and CRMP2 interact with WAVE1, it is possible that these proteins work together in a pathway regulating the development of pathologic pain (Kawano et al., 2005).

\section{srGAP3 regulates dendritic spine initiation}

Another protein intimately involved in the development of dendritic spines, through regulation of the actin cytoskeleton, WAVE1, and Rac1, which has recently implicated in the initiation of neuropathic pain is srGAP3, also known as mental retardation-associated GTPase activating protein or WAVEassociated Rac GTPase-activating protein (Endris et al., 2002; Soderling et al., 2002; Blockus and Chédotal, 2016). This protein is highly expressed in the CNS during development and has been identified in neurons of spinal dorsal horn as well as dorsal root ganglia (DRG) (Bacon et al., 2009; Z. B. Chen et al., 2012). As a downstream component of the Slit-Robo signaling system, this protein is responsible for guiding synaptic connections, determining maturation of neurites into axons or dendrites, regulating neuronal progenitors during development (Wong et al., 2001; Mattar et al., 2004; Yao et al., 2008; Bacon et al., 2011; I. H. Kim et al., 2012; Koschützke et al., 2015), and it is implicated in the early stages of spine initiation. Expression of srGAP3 increases the number of thin, filopodial/immature-type dendritic spines (Waltereit et al., 2008; K. Chen et al., 2011), which are more dynamic than mushroom-shaped spines and are thought to be involved in initial synaptogenesis rather than long-term memory formation. Additionally, srGAP3 overexpression decreases the number and size of inhibitory synapses in gephyrin-positive cultured hippocampal neurons, suggesting involvement in determining the ratio of excitatory to inhibitory synapses, a parameter known to be biased toward excitation in neuropathic pain states (Subramanian and Nedivi, 2016). While these latter findings were reported in the context of autism spectrum disorders, the changes in spine formation might be applicable to other neurologic disorders, including neuropathic pain (Bertram et al., 2016; Pérez et al., 2016; Hlushchenko et al., 2018).

\section{The GAP in srGAP3}

There are three primary functional domains of srGAP3: an inverse Fes/Cip4 homology-Bin/Amphiphysin/Rvs167 (IF-BAR) domain, a Rho GAP domain, and a Src Homology 3 (SH3) domain (Fig. 4). Each of these domains is responsible for targeting interactions of srGAP3 with other proteins, specifically those involved in regulation of the actin cytoskeleton. The GAP domain is specific for Rac1, and it inhibits Rac1-dependent dendritic-spine formation by accelerating GTP hydrolysis (Soderling et al., 2002; Yang et al., 2006). The interaction between srGAP3 and Rac1 was confirmed in cultured cerebellar granule neurons, where srGAP3 inhibited Rac1-dependent neurite outgrowth. Transfection with an srGAP3 construct lacking the GAP domain did not have this effect on neurite outgrowth (Soderling et al., 2002). This points to a role for srGAP3 in dendritic spine regulation through modulation of Racl activity (Zhang et al., 2014).

\section{SH3 adaptor region}

Through its SH3 domain, srGAP3 interacts with the intracellular component of the Robol receptor, resulting in destabilization of the actin cytoskeleton. The SH3 domain also interacts with WAVE1 in the proline-rich region between amino acids 322-332 and 425-431. Mice expressing a WAVE1 construct, lacking the srGAP3 recognition domain, displayed reduced dendritic spine 


\section{srGAP3 Domains}

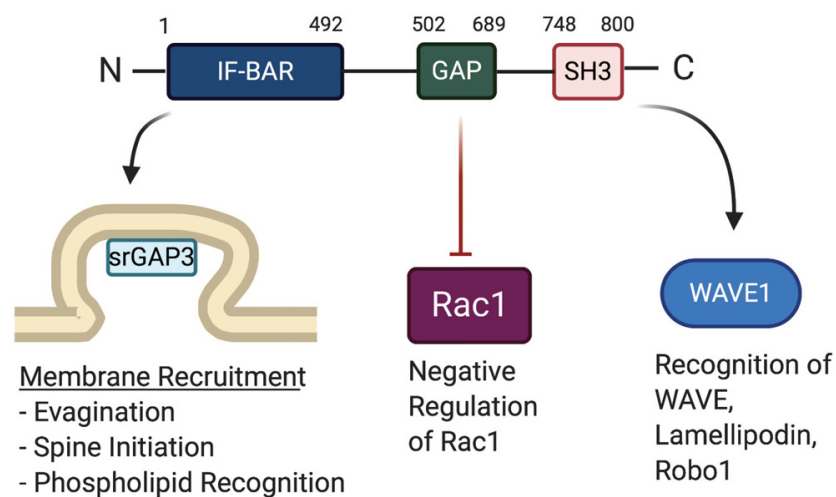

Figure 4. Functional domains of srGAP3 drive diverse interactions. The structure of srGAP3 is highly conserved with other srGAP proteins and contains three unique domains. At the $\mathrm{N}$ terminal region is an IF-BAR domain that is composed of $\alpha$-helical coils that bind the membrane as homodimers through recognition of specific membrane phospholipids, such as PIP2 and PIP3. In the central region, there is a GAP domain, which is specific for and inhibits the activity of Rac1. Toward the C-terminal tail of the protein is an SH3 domain that acts as a scaffolding adaptor for recognition of several different interactors, such as WAVE1, lamellopodin, and its canonical receptor Robo1. These regions allow srGAP3 to mediate a variety of different intracellular functions through interactions with a diverse set of interaction partners. The numbers depict the specific amino acid residues where each domain begins and ends in the human srGAP3 protein.

density, altered synaptic plasticity, and specific defects in memory retention (Carlson et al., 2011). This finding confirmed that srGAP3 anchored to WAVE1 controls cytoskeletal events essential for normal developmental progression and synaptic plasticity in hippocampal neurons (Soderling et al., 2007). In addition to its interactions with WAVE1, a single PXXP motif sequence in the C-terminal disordered region of srGAP3 mediates interactions with endophilin-A1 and A2, amphiphysin, and Grb2, which are involved in membrane deformation and growth regulation. These interactions occur along linear interfaces located within the $\mathrm{SH} 3$ recognition regions of the partner proteins, implying that this domain can act as a scaffolding adaptor that connects the upstream Robo receptor to different signaling networks (Kurochkina and Guha, 2013; Wuertenberger and Groemping, 2015). This finding suggests that srGAP3 is functionally coupled to unique signaling outcomes arising from a singular upstream binding event and that srGAP3 is involved in diverse cellular events involving cytoskeletal reorganization.

\section{The IF-BAR domain and membrane recognition}

The IF-BAR domain of srGAP3 recognizes specific membrane lipids, such as phosphatidylinositol 4,5-bisphosphate (PIP2) and phosphatidylinositol $(3,4,5)$-trisphosphate (PIP3), which drives membrane recruitment (Coutinho-Budd et al., 2012). Membrane association promotes local outward curvature, which is the first step in dendritic spine formation from early filopodial protrusions (Endris et al., 2011; Ma et al., 2013). This recognition occurs through positively charged residues on the convex surface of the IF-BAR domain interacting with the negatively charged head groups of membrane phospholipids. Mutation of these residues from positively charged arginine and lysine to glutamic acid results in reduced membrane recruitment of srGAP3, demonstrating the importance of these residues for membrane recognition. Neuronal cultures from mice lacking srGAP3 are deficient in filopodial protrusions and exhibit reduced synaptogenesis. Expression of the IF-BAR domain of srGAP3 is sufficient to rescue this phenotype and implicates this domain in the early stages of dendritic spine formation. Furthermore, Carlson et al. (2011) found that, while srGAP3 is essential for early stages of spine formation, it is not necessary for the maintenance of already established dendritic spines. Consistent with evidence for an essential role of the IF-BAR domain in spine initiation, splice variant of srGAP3 with interruption of the IF-BAR domain results in severe intellectual disability, known as 3p Syndrome (Endris et al., 2002). If the truncation of srGAP3 occurs after the IF-BAR domain, then intellectual disability does not occur and patients are otherwise normal (Ba et al., 2013; Ellery et al., 2014). Additionally, microduplication of the 3p25 locus of the srGAP3 gene has been associated with hereditary psychotic illness, further implicating srGAP3 in neuronal processing (Wilson et al., 2011; Waltereit et al., 2012; Eszlari et al., 2019). This association was confirmed in an animal model in which mice lacking a critical exon within the IF-BAR domain coding region exhibited profound deficits in learning and memory-related functions (Carlson et al., 2011). Together, these results demonstrate the importance of the IF-BAR region of srGAP3 for membrane recognition and dendritic spine initiation.

\section{srGAP3 in neuropathic pain}

Recent experimental evidence has suggested that srGAP3 is involved in dendritic spine dysgenesis in neuropathic pain in addition to its well-defined role in normal spine formation. In a model of paclitaxel-induced peripheral neuropathy (PIPN), Z. Chen et al. (2020) clearly demonstrated increased srGAP3 protein abundance in the superficial layers of the spinal dorsal horn in the early phase of neuropathic pain development. Additionally, siRNA-mediated silencing of srGAP3 reduced mechanical hypersensitivity and partially reversed the aberrant spine phenotype when delivered during the initiation of neuropathic pain. Moreover, adeno-associated virus-mediated overexpression of srGAP3 in the spinal dorsal horn produced mechanical hypersensitivity and corresponding changes to dendritic spine architecture. Interestingly, when these manipulations were applied during the maintenance phase of neuropathic pain, when mature dendritic spines are more prevalent, these effects were not observed. Together, these results point to a clear role for srGAP3 in the initiation of neuropathic pain and dendritic spine dysgenesis ( $\mathrm{Z}$. B. Chen et al., 2012; Z. Chen et al., 2020).

\section{Using srGAP3 to identify other filopodial proteins}

The protein composition of nascent filopodia has been difficult to study compared with other more robust synaptic structures because of their transient nature. Recent work has overcome the technical limitations preventing characterization of protein elements within nascent dendritic spines by using srGAP3 as a marker of these structures. Using an srGAP3 construct coupled with the biotin ligase BirA, Spence et al. (2019) identified $\sim 60$ individual proteins within these fleeting structures using in vivo proximity labeling in hippocampal neurons. The findings from this work support prior data indicating an interaction between srGAP3 and WAVE1 to regulate Arp2/3-mediated actin polymerization. Furthermore, a previously uncharacterized protein was discovered, the Capping protein Arp2/3 myosinILinker (CARMIL3), which is essential for actin remodeling and formatting of the branched actin networks observed in mature dendritic spines. Loss of CARMIL3 through genetic editing using CRISPR/Cas9-based approaches resulted in impaired transition from immature to mature spines and reduced AMPA receptormediated EPSCs. This evidence supports the idea that distinct 
molecular complexes regulate the formation and maturation of dendritic spines by using srGAP3 as a marker of the initial stages of spine development. Extending this work by performing similar characterization of nascent synapses in models of neuropathic pain will be essential for determining whether these regulatory elements are altered in painful states and might identify painrelated changes in the molecular composition of dendritic spines.

\section{A model of synergistic action for combating aberrant nociception}

A temporal targeting strategy

Accumulating evidence has shown that srGAP3 is intimately involved in the initiation of dendritic spine formation from filopodial dendritic shaft protrusions whereas Racl is involved in the maintenance of mature spines. From these findings, it is possible to construct a synergistic temporal targeting model supporting complementary roles for the regulation of spines by srGAP3 and Racl at distinct stages in the spine life cycle. In such a model, mutual targeting of srGAP3 and Rac1 during the onset and development of neuropathic pain might produce stronger antinociceptive outcomes. There is recent evidence supporting the validity of this concept using a rat model of PIPN (Z. Chen et al., 2020). Activity of srGAP3 was genetically silenced using an intrathecal siRNA construct, and Rac1 was inhibited using intrathecal NSC23766. Each of these interventions produced moderate reversal of mechanical hypersensitivity when delivered alone during the appropriate temporal window. However, when they were used sequentially, the reversal of mechanical hypersensitivity was almost complete. This finding is in line with prior evidence that Rac1 inhibition was most effective during later stages after SCI and that earlier application did not have a significant effect on the development of neuropathic pain (Zhao et al., 2016). Collectively, these lines of evidence support the temporal targeting strategy and highlight complementary, yet distinct, roles for srGAP3 and Rac1 in dendritic spine dysgenesis.

WAVE1 represents a hub for cytoskeletal actin remodeling where signaling pathways for Rac1 and srGAP3 converge to dynamically regulate dendritic spine development and synaptic plasticity. The N-terminal Scar homology domain of WAVE1 binds a core unit of four proteins that regulate Racl activity and direct its action toward sites of actin reorganization. Additionally, the proline-rich region of WAVE1 has multiple sites that allow recognition of SH3-domain-containing proteins, such as srGAP3. Finally, the C-terminal verprolin-cofilin-acidic domain promotes the interaction of WAVE1 with the Arp $2 / 3$ complex, which initiates nucleation of a daughter actin filament and promotes the formation of branched actin networks. Furthermore, WAVE1 KO mice show deficits in sensorimotor function and dendritic spine formation, reduced capacity for synaptic plasticity, and poor performance in cognitive tests (Soderling et al., 2007). This positions the WAVE1 complex as a key regulator of dendritic spine formation at the intersection of srGAP3 and Rac1 and provides a prime target for future studies exploring the molecular mediators of structural plasticity in neuropathic pain.

In conclusion, CNS dendritic spine dysgenesis is a core feature of maladaptive synaptic plasticity observed in neuropathic pain and is thought to underlie central sensitization. The molecular regulators of dendritic spine initiation and maturation, srGAP3 and Rac1, have been implicated in development of pathologic synaptic plasticity through regulation of the actin cytoskeleton. Preclinical studies targeting these proteins have demonstrated efficacy in ameliorating the hypersensitivity associated with neuropathic pain, but many questions remain, particularly concerning the role of srGAP3 in this process (Table 1). The complementary action of srGAP3 and Rac1 inhibition produces enhanced antinociception and implies a synergistic relationship between these regulatory proteins. This effect likely arises from the mutual inhibition of Rac1 activity, with NSC23766 blocking the GEFs Tiam1 and Trio, and silencing of srGAP3 blocking its inhibitory activity toward Rac1, which would result in dual blockade of Racl by preventing activation through GEFs as well as srGAP3-mediated inactivation (Marei and Malliri, 2017). Despite both interventions targeting Rac1, they each target a specific phase of the Racl activity cycle and are therefore poised to increase the overall inhibition of Racl compared with a single intervention. However, these effects were observed using siRNAmediated silencing of srGAP3, which inhibits all three domains of srGAP3 equally and therefore precludes dissection of domainspecific effects. Therefore, it is possible the effects stem from a different mechanism that does not involve the GAP domain, but instead relies on the function of the IF-BAR or SH3 components of srGAP3. Involvement of the $\mathrm{SH} 3$ domain would implicate interactions between srGAP3 and its other known binding partners, lamellipodin, Robo1, and WAVE1 in spine dysgenesis. Additionally, given the importance of the IF-BAR domain in membrane recognition and initiation of dendritic spine development, it is possible that interference with this domain alone is sufficient to prevent spine formation in neuropathic pain.

Dissection of the roles of these domains should be the focus of future studies investigating how srGAP3 contributes to mechanical hypersensitivity and spine dysgenesis. Furthermore, these findings regarding pain have been drawn from measures of altered dendritic spine structure, such as imaging of tissue sections, rather than functional studies. To gain a more complete perspective on the role of dendritic spines in pain, it is necessary to repeat these experiments using ex vivo slice electrophysiology to measure functional plasticity and understand the networklevel effects of these molecular targets. Additionally, questions remain regarding the precise mechanisms underlying the desirable effects of NSC23766 on spine maturation and neuropathic pain. Future studies investigating the exact molecular pathways modulated by NSC23766 application and srGAP3 inhibition are necessary to understand this system and its implications for the development of novel therapeutics. Currently, there are no in vivo mechanistic studies exploring the function of these interventions in the context of neuropathic pain. Finally, a complete characterization of the interaction network for srGAP3 at dendritic spines in the setting of neuropathic pain is essential for understanding these interactions for the development of antinociceptive targets.

\section{References}

Alles SR, Smith PA (2018) Etiology and pharmacology of neuropathic pain. Pharmacol Rev 70:315-347.

Anthony H, Karel S (2009) Experience-dependent structural synaptic plasticity in the mammalian brain. Nat Rev Neurosci 10:647-658.

Ba W, van der Raadt J, Nadif Kasri N (2013) Rho GTPase signaling at the synapse: implications for intellectual disability. Exp Cell Res 319:23682374.

Bacon C, Endris V, Rappold G (2009) Dynamic expression of the Slit-Robo GTPase activating protein genes during development of the murine nervous system. J Comp Neurol 513:224-236.

Bacon C, Endris V, Andermatt I, Niederkofler V, Waltereit R, Bartsch D, Stoeckli ET, Rappold G (2011) Evidence for a role of srGAP3 in the positioning of commissural axons within the ventrolateral funiculus of the mouse spinal cord. PLoS One 6:e19887.

Bandaru SP, Liu S, Waxman SG, Tan AM (2015) Dendritic spine dysgenesis contributes to hyperreflexia after spinal cord injury. J Neurophysiol 113:1598-1615. 
Benson CA, Fenrich KK, Olson KL, Patwa S, Bangalore L, Waxman SG, Tan AM (2020) Dendritic spine dynamics after peripheral nerve injury: an intravital structural study. J Neurosci 40:4297-4308.

Berry KP, Nedivi E (2017) Spine dynamics: are they all the same? Neuron 96:43-55.

Bertram J, Koschützke L, Pfannmöller JP, Esche J, van Diepen L, Kuss AW, Hartmann B, Bartsch D, Lotze M, von Bohlen Und Halbach O (2016) Morphological and behavioral characterization of adult mice deficient for SrGAP3. Cell Tissue Res 366:1-11.

Blockus H, Chédotal A (2016) Slit-Robo signaling. Development 143:30373044.

Bongmba OY, Martinez LA, Elhardt ME, Butler K, Tejada-Simon MV (2011) Modulation of dendritic spines and synaptic function by Rac1: a possible link to Fragile X syndrome pathology. Brain Res 1399:79-95.

Borovac J, Bosch M, Okamoto K (2018) Regulation of actin dynamics during structural plasticity of dendritic spines: signaling messengers and actinbinding proteins. Mol Cell Neurosci 91:122-130.

Bustelo XR, Ojeda V, Barreira M, Sauzeau V, Castro-Castro A (2012) Racing to the plasma membrane: the long and complex work commute of Rac1 during cell signaling. Small GTPases 3:60-66.

Cao XC, Pappalardo LW, Waxman SG, Tan AM (2017) Dendritic spine dysgenesis in superficial dorsal horn sensory neurons after spinal cord injury. Mol Pain 13:1744806916688016.

Carlson BR, Lloyd KE, Kruszewski A, Kim IH, Rodriguiz RM, Heindel C, Faytell M, Dudek SM, Wetsel WC, Soderling SH (2011) WRP/srGAP3 facilitates the initiation of spine development by an inverse F-BAR domain, and its loss impairs long-term memory. J Neurosci 31:2447-2460.

Chen B, Chou HT, Brautigam CA, Xing W, Yang S, Henry L, Doolittle LK, Walz T, Rosen MK (2017) Rac1 GTPase activates the WAVE regulatory complex through two distinct binding sites. Elife 6:e29795.

Chen K, Mi YJ, Ma Y, Fu HL, Jin WL (2011) The mental retardation associated protein, srGAP3 negatively regulates VPA-induced neuronal differentiation of Neuro2A cells. Cell Mol Neurobiol 31:675-686.

Chen LY, Rex CS, Babayan AH, Kramár EA, Lynch G, Gall CM, Lauterborn JC (2010) Physiological activation of synaptic Rac $>$ PAK (p-21 activated kinase) signaling is defective in a mouse model of fragile $\mathrm{X}$ syndrome. J Neurosci 30:10977-10984

Chen Y, Luo F, Yang C, Kirkmire CM, Wang ZJ (2009) Acute inhibition of $\mathrm{Ca}^{2+} /$ calmodulin-dependent protein kinase II reverses experimental neuropathic pain in mice. J Pharmacol Exp Ther 330:650-659.

Chen Z, Borek D, Padrick SB, Gomez TS, Metlagel Z, Ismail AM, Umetani J, Billadeau DD, Otwinowski Z, Rosen MK (2010) Structure and control of the actin regulatory WAVE complex. Nature 468:533-538.

Chen Z, Zhang S, Nie B, Huang J, Han Z, Chen X, Bai X, Ouyang H (2020) Distinct roles of srGAP3-Rac1 in the initiation and maintenance phases of neuropathic pain induced by paclitaxel. J Physiol 598:2415-2430.

Chen ZB, Zhang HY, Zhao JH, Zhao W, Zhao D, Zheng LF, Zhang XF, Liao XP, Yi XN (2012) Slit-Robo GTPase-activating proteins are differentially expressed in murine dorsal root ganglia: modulation by peripheral nerve injury. Anat Rec (Hoboken) 295:652-660

Chklovskii DB (2004) Synaptic connectivity and neuronal morphology: two sides of the same coin. Neuron 43:609-617.

Cingolani LA, Goda Y (2008) Actin in action: the interplay between the actin cytoskeleton and synaptic efficacy. Nat Rev Neurosci 9:344-356.

Coutinho-Budd J, Ghukasyan V, Zylka MJ, Polleux F (2012) The F-BAR domains from srGAP1, srGAP2 and srGAP3 regulate membrane deformation differently. J Cell Sci 125:3390-3401.

Danelon V, Goldner R, Martinez E, Gokhman I, Wang K, Yaron A, Tran TS (2020) Modular and distinct PlexinA4/Farp2/Rac1 signaling controls dendrite morphogenesis. J Neurosci 40:5413-5430.

Eden S, Rohatgi R, Podtelejnikov AV, Mann M, Kirschner MW (2002) Mechanism of regulation of WAVE1-induced actin nucleation by Rac1 and Nck. Nature 418:790-793.

Ellery PM, Ellis RJ, Holder SE (2014) Interstitial 3p25 deletion in a patient with features of $3 p$ deletion syndrome: further evidence for the role of SRGAP3 in mental retardation. Clin Dysmorphol 23:29-31.

Endris V, Wogatzky B, Leimer U, Bartsch D, Zatyka M, Latif F, Maher ER, Tariverdian G, Kirsch S, Karch D, Rappold GA (2002) The novel RhoGTPase activating gene MEGAP/srGAP3 has a putative role in severe mental retardation. Proc Natl Acad Sci USA 99:11754-11759.
Endris V, Haussmann L, Buss E, Bacon C, Bartsch D, Rappold G (2011) SrGAP3 interacts with lamellipodin at the cell membrane and regulates Rac-dependent cellular protrusions. J Cell Sci 124:3941-3955.

Eom T, Antar LN, Singer RH, Bassell GJ (2003) Localization of a beta-actin messenger ribonucleoprotein complex with zipcode-binding protein modulates the density of dendritic filopodia and filopodial synapses. J Neurosci 23:10433-10444.

Eszlari N, Millinghoffer A, Petschner P, Gonda X, Baksa D, Pulay AJ, Réthelyi JM, Breen G, Deakin JFW, Antal P, Bagdy G, Juhasz G (2019) Genome-wide association analysis reveals KCTD12 and miR-383-binding genes in the background of rumination. Transl Psychiatry 9:119.

Ghosh A, Peduzzi S, Snyder M, Schneider R, Starkey M, Schwab ME (2012) Heterogeneous spine loss in layer 5 cortical neurons after spinal cord injury. Cereb Cortex 22:1309-1317.

Golden SA, Christoffel DJ, Heshmati M, Hodes GE, Magida J, Davis K, Cahill ME, Dias C, Ribeiro E, Ables JL, Kennedy PJ, Robison AJ, Gonzalez-Maeso J, Neve RL, Turecki G, Ghose S, Tamminga CA, Russo SJ (2013) Epigenetic regulation of RAC1 induces synaptic remodeling in stress disorders and depression. Nat Med 19:337-344.

Gonzalez-Billault C, Muñoz-Llancao P, Henriquez DR, Wojnacki J, Conde C, Caceres A (2012) The role of small GTPases in neuronal morphogenesis and polarity. Cytoskeleton (Hoboken) 69:464-485.

González-Tapia D, González-Tapia DC, Vázquez-Hernández N, MartínezTorres NI, Flores-Soto M, González-Burgos I (2020) Modifications to cytoskeleton-associated proteins in dendritic spines underlie the adaptive plasticity involved in long term reference memory. Neurobiol Learn Mem 172:107247.

Goshima Y, Yamashita N, Nakamura F, Sasaki Y (2016) Regulation of dendritic development by semaphorin $3 \mathrm{~A}$ through novel intracellular remote signaling. Cell Adh Migr 10:627-640.

Guan Y, Borzan J, Meyer RA, Raja SN (2006) Windup in dorsal horn neurons is modulated by endogenous spinal $\mu$-opioid mechanisms. J Neurosci 26:4298-4307.

Guo Y, Benson C, Hill M, Henry S, Effraim P, Waxman SG, Dib-Hajj S, Tan AM (2018) Therapeutic potential of Pak1 inhibition for pain associated with cutaneous burn injury. Mol Pain 14:1744806918788648.

Hagerman RJ, Coffey SM, Maselli R, Soontarapornchai K, Brunberg JA, Leehey MA, Zhang L, Gane LW, Fenton-Farrell G, Tassone F, Hagerman PJ (2007) Neuropathy as a presenting feature in fragile X-associated tremor/ataxia syndrome. Am J Med Genet A 143A:2256-2260.

Hayashi-Takagi A, Yagishita S, Nakamura M, Shirai F, Wu YI, Loshbaugh AL, Kuhlman B, Hahn KM, Kasai H (2015) Labelling and optical erasure of synaptic memory traces in the motor cortex. Nature 525:333-338.

Hayashi Y, Majewska AK (2005) Dendritic spine geometry: functional implication and regulation. Neuron 46:529-532.

Hayashi Y, Shi SH, Esteban JA, Piccini A, Poncer JC, Malinow R (2000) Driving AMPA receptors into synapses by LTP and CaMKII: requirement for GluR1 and PDZ domain interaction. Science 287:2262-2267.

He X, Kuo YC, Rosche TJ, Zhang X (2013) Structural basis for autoinhibition of the guanine nucleotide exchange factor FARP2. Structure 21:355-364.

Hedrick NG, Harward SC, Hall CE, Murakoshi H, McNamara JO, Yasuda R (2016) Rho GTPase complementation underlies BDNF-dependent homo- and heterosynaptic plasticity. Nature 538:104-108.

Hering H, Sheng M (2001) Dendritic spines: structure, dynamics and regulation. Nat Rev Neurosci 2:880-888.

Hill TC, Zito K (2013) LTP-induced long-term stabilization of individual nascent dendritic spines. J Neurosci 33:678-686.

Hlushchenko I, Koskinen M, Hotulainen P (2016) Dendritic spine actin dynamics in neuronal maturation and synaptic plasticity. Cytoskeleton (Hoboken) 73:435-441.

Hlushchenko I, Khanal P, Abouelezz A, Paavilainen VO, Hotulainen P (2018) ASD-associated de novo mutations in five actin regulators show both shared and distinct defects in dendritic spines and inhibitory synapses in cultured hippocampal neurons. Front Cell Neurosci 12:217.

Jaudon F, Raynaud F, Wehrlé R, Bellanger JM, Doulazmi M, Vodjdani G, Gasman S, Fagni L, Dusart I, Debant A, Schmidt S (2015) The RhoGEF DOCK10 is essential for dendritic spine morphogenesis. Mol Biol Cell 26:2112-2127.

Jensen TS, Baron R, Haanpää M, Kalso E, Loeser JD, Rice AS, Treede RD (2011) A new definition of neuropathic pain. Pain 152:2204-2205.

Ji RR, Donnelly CR, Nedergaard M (2019) Astrocytes in chronic pain and itch. Nat Rev Neurosci 20:667-685. 
Kalpachidou T, Spiecker L, Kress M, Quarta S (2019) Rho GTPases in the physiology and pathophysiology of peripheral sensory neurons. Cells 8:591.

Kawano Y, Yoshimura T, Tsuboi D, Kawabata S, Kaneko-Kawano T, Shirataki H, Takenawa T, Kaibuchi K (2005) CRMP-2 is involved in kinesin-1-dependent transport of the Sra-1/WAVE1 complex and axon formation. Mol Cell Biol 25:9920-9935.

Kawano T, Zoga V, Gemes G, McCallum JB, Wu HE, Pravdic D, Liang MY, Kwok WM, Hogan Q, Sarantopoulos C (2009) Suppressed $\mathrm{Ca}^{2+} / \mathrm{CaM} /$ CaMKII-dependent $\mathrm{K}_{\mathrm{ATP}}$ channel activity in primary afferent neurons mediates hyperalgesia after axotomy. Proc Natl Acad Sci USA 106:87258730.

Kim IH, Carlson BR, Heindel CC, Kim H, Soderling SH (2012) Disruption of wave-associated Rac GTPase-activating protein (Wrp) leads to abnormal adult neural progenitor migration associated with hydrocephalus. J Biol Chem 287:39263-39274.

Kim SK, Hayashi H, Ishikawa T, Shibata K, Shigetomi E, Shinozaki Y, Inada H, Roh SE, Kim SJ, Lee G, Bae H, Moorhouse AJ, Mikoshiba K, Fukazawa Y, Koizumi S, Nabekura J (2016) Cortical astrocytes rewire somatosensory cortical circuits for peripheral neuropathic pain. J Clin Invest 126:1983-1997.

Kim Y, Sung JY, Ceglia I, Lee KW, Ahn JH, Halford JM, Kim AM, Kwak SP, Park JB, Ho Ryu S, Schenck A, Bardoni B, Scott JD, Nairn AC, Greengard P (2006) Phosphorylation of WAVE1 regulates actin polymerization and dendritic spine morphology. Nature 442:814-817.

Koschützke L, Bertram J, Hartmann B, Bartsch D, Lotze M, von Bohlen und Halbach O (2015) SrGAP3 knockout mice display enlarged lateral ventricles and specific cilia disturbances of ependymal cells in the third ventricle. Cell Tissue Res 361:645-650.

Kurochkina N, Guha U (2013) SH3 domains: modules of protein-protein interactions. Biophys Rev 5:29-39.

Lee HJ, Choi EJ, Nahm FS, Yoon IY, Lee PB (2018) Prevalence of unrecognized depression in patients with chronic pain without a history of psychiatric diseases. Korean J Pain 31:116-124.

Li LZ, Yin N, Li XY, Miao Y, Cheng S, Li F, Zhao GL, Zhong SM, Wang X, Yang XL, Wang Z (2019) Rac1 modulates excitatory synaptic transmission in mouse retinal ganglion cells. Neurosci Bull 35:673-687.

Ma Y, Mi YJ, Dai YK, Fu HL, Cui DX, Jin WL (2013) The inverse F-BAR domain protein srGAP2 acts through srGAP3 to modulate neuronal differentiation and neurite outgrowth of mouse neuroblastoma cells. PLoS One 8:e57865.

Marei H, Malliri A (2017) Rac1 in human diseases: the therapeutic potential of targeting Racl signaling regulatory mechanisms. Small GTPases 8:139-163.

Marston DJ, Anderson KL, Swift MF, Rougie M, Page C, Hahn KM, Volkmann N, Hanein D (2019) High Racl activity is functionally translated into cytosolic structures with unique nanoscale cytoskeletal architecture. Proc Natl Acad Sci USA 116:1267-1272.

Matsuzaki M, Honkura N, Ellis-Davies GC, Kasai H (2004) Structural basis of long-term potentiation in single dendritic spines. Nature 429:761-766.

Mattar P, Britz O, Johannes C, Nieto M, Ma L, Rebeyka A, Klenin N, Polleux F, Guillemot F, Schuurmans C (2004) A screen for downstream effectors of Neurogenin2 in the embryonic neocortex. Dev Biol 273:373-389.

McKinney RA (2010) Excitatory amino acid involvement in dendritic spine formation, maintenance and remodelling. J Physiol 588:107-116.

Melemedjian OK, Tillu DV, Asiedu MN, Mandell EK, Moy JK, Blute VM, Taylor CJ, Ghosh S, Price TJ (2013) BDNF regulates atypical PKC at spinal synapses to initiate and maintain a centralized chronic pain state. Mol Pain 9:12.

Miki H, Suetsugu S, Takenawa T (1998) WAVE, a novel WASP-family protein involved in actin reorganization induced by Rac. EMBO J 17:69326941.

Murakoshi H, Yasuda R (2012) Postsynaptic signaling during plasticity of dendritic spines. Trends Neurosci 35:135-143.

Nguyen MV, Du F, Felice CA, Shan X, Nigam A, Mandel G, Robinson JK, Ballas N (2012) MeCP2 is critical for maintaining mature neuronal networks and global brain anatomy during late stages of postnatal brain development and in the mature adult brain. J Neurosci 32:10021-10034.

Park I, Kim HJ, Kim Y, Hwang HS, Kasai H, Kim JH, Park JW (2019) Nanoscale imaging reveals miRNA-mediated control of functional states of dendritic spines. Proc Natl Acad Sci USA 116:9616-9621.
Paskus JD, Herring BE, Roche KW (2020) Kalirin and Trio: rhoGEFs in synaptic transmission, plasticity, and complex brain disorders. Trends Neurosci 43:505-518.

Patwa S, Benson CA, Dyer L, Olson KL, Bangalore L, Hill M, Waxman SG, Tan AM (2019) Spinal cord motor neuron plasticity accompanies second-degree burn injury and chronic pain. Physiol Rep 7:e14288.

Payapilly A, Malliri A (2018) Compartmentalisation of RAC1 signalling. Curr Opin Cell Biol 54:50-56.

Pennucci R, Gucciardi I, de Curtis I (2019) Rac1 and Rac3 GTPases differently influence the morphological maturation of dendritic spines in hippocampal neurons. PLoS One 14:e0220496.

Pérez C, Sawmiller D, Tan J (2016) The role of heparan sulfate deficiency in autistic phenotype: potential involvement of Slit/Robo/srGAPs-mediated dendritic spine formation. Neural Dev 11:11.

Portera-Cailliau C, Pan DT, Yuste R (2003) Activity-regulated dynamic behavior of early dendritic protrusions: evidence for different types of dendritic filopodia. J Neurosci 23:7129-7142.

Price TJ, Rashid MH, Millecamps M, Sanoja R, Entrena JM, Cervero F (2007) Decreased nociceptive sensitization in mice lacking the fragile $\mathrm{X}$ mental retardation protein: role of mGluR1/5 and mTOR. J Neurosci 27:1395813967.

Pyronneau A, He Q, Hwang JY, Porch M, Contractor A, Zukin RS (2017) Aberrant Rac1-cofilin signaling mediates defects in dendritic spines, synaptic function, and sensory perception in fragile X syndrome. Sci Signal 10:eaan0852.

Raemaekers T, Peric A, Baatsen P, Sannerud R, Declerck I, Baert V, Michiels C, Annaert W (2012) ARF6-mediated endosomal transport of telencephalin affects dendritic filopodia-to-spine maturation. EMBO J 31:32523269.

Risher WC, Patel S, Kim IH, Uezu A, Bhagat S, Wilton DK, Pilaz LJ, Singh Alvarado J, Calhan OY, Silver DL, Stevens B, Calakos N, Soderling SH, Eroglu C (2014) Astrocytes refine cortical connectivity at dendritic spines. Elife 3:e04047.

Risher WC, Kim N, Koh S, Choi JE, Mitev P, Spence EF, Pilaz LJ, Wang D, Feng G, Silver DL, Soderling SH, Yin HH, Eroglu C (2018) Thrombospondin receptor $\alpha 2 \delta$-1 promotes synaptogenesis and spinogenesis via postsynaptic Rac1. J Cell Biol 217:3747-3765.

Rodriguez-Revenga L, Madrigal I, Pagonabarraga J, Xunclà M, Badenas C, Kulisevsky J, Gomez B, Milà M (2009) Penetrance of FMR1 premutation associated pathologies in fragile X syndrome families. Eur J Hum Genet 17:1359-1362.

Sandkühler J (2007) Understanding LTP in pain pathways. Mol Pain 3:9.

Schaks M, Singh SP, Kage F, Thomason P, Klünemann T, Steffen A, Blankenfeldt W, Stradal TE, Insall RH, Rottner K (2018) Distinct interaction sites of Rac GTPase with WAVE regulatory complex have nonredundant functions in vivo. Curr Biol 28:3674-3684.e6.

Seabra MC (1998) Membrane association and targeting of prenylated Raslike GTPases. Cell Signal 10:167-172.

Segal M (2017) Dendritic spines: morphological building blocks of memory. Neurobiol Learn Mem 138:3-9.

Soderling SH, Binns KL, Wayman GA, Davee SM, Ong SH, Pawson T, Scott JD (2002) The WRP component of the WAVE-1 complex attenuates Rac-mediated signalling. Nat Cell Biol 4:970-975.

Soderling SH, Guire ES, Kaech S, White J, Zhang F, Schutz K, Langeberg LK, Banker G, Raber J, Scott JD (2007) A WAVE-1 and WRP signaling complex regulates spine density, synaptic plasticity, and memory. J Neurosci 27:355-365.

Spence EF, Dube S, Uezu A, Locke M, Soderblom EJ, Soderling SH (2019) In vivo proximity proteomics of nascent synapses reveals a novel regulator of cytoskeleton-mediated synaptic maturation. Nat Commun 10:386.

Subramanian J, Nedivi E (2016) Filling the (SR)GAP in excitatory/inhibitory balance. Neuron 91:205-207.

Sung JY, Engmann O, Teylan MA, Nairn AC, Greengard P, Kim Y (2008) WAVE1 controls neuronal activity-induced mitochondrial distribution in dendritic spines. Proc Natl Acad Sci USA 105:3112-3116.

Tan AM (2015) Dendritic spine dysgenesis in neuropathic pain. Prog Mol Biol Transl Sci 131:385-408.

Tan AM, Waxman SG (2015) Dendritic spine dysgenesis in neuropathic pain. Neurosci Lett 601:54-60.

Tan AM, Stamboulian S, Chang YW, Zhao P, Hains AB, Waxman SG, Hains BC (2008) Neuropathic pain memory is maintained by Racl-regulated 
dendritic spine remodeling after spinal cord injury. J Neurosci 28:1317313183.

Tan AM, Choi JS, Waxman SG, Hains BC (2009) Dendritic spine remodeling after spinal cord injury alters neuronal signal processing. J Neurophysiol 102:2396-2409.

Tan AM, Chang YW, Zhao P, Hains BC, Waxman SG (2011) Rac1-regulated dendritic spine remodeling contributes to neuropathic pain after peripheral nerve injury. Exp Neurol 232:222-233.

Tan AM, Samad OA, Fischer TZ, Zhao P, Persson AK, Waxman SG (2012) Maladaptive dendritic spine remodeling contributes to diabetic neuropathic pain. J Neurosci 32:6795-6807.

Tan AM, Samad OA, Liu S, Bandaru S, Zhao P, Waxman SG (2013) Burn injury-induced mechanical allodynia is maintained by Rac1-regulated dendritic spine dysgenesis. Exp Neurol 248:509-519.

Tashiro A, Yuste R (2004) Regulation of dendritic spine motility and stability by Racl and Rho kinase: evidence for two forms of spine motility. Mol Cell Neurosci 26:429-440.

Todd AJ (2010) Neuronal circuitry for pain processing in the dorsal horn. Nat Rev Neurosci 11:823-836.

Tolias KF, Bikoff JB, Kane CG, Tolias CS, Hu L, Greenberg ME (2007) The Rac1 guanine nucleotide exchange factor Tiam1 mediates EphB receptordependent dendritic spine development. Proc Natl Acad Sci USA 104:7265-7270.

Tsai SY, Hayashi T, Harvey BK, Wang Y, Wu WW, Shen RF, Zhang Y, Becker KG, Hoffer BJ, Su TP (2009) Sigma-1 receptors regulate hippocampal dendritic spine formation via a free radical-sensitive mechanism involvingRac1xGTPpathway.ProcNatlAcadSciUSA106:22468-22473.

Tyrtyshnaia A, Manzhulo I (2020) Neuropathic pain causes memory deficits and dendrite tree morphology changes in mouse hippocampus. J Pain Res 13:345-354.

Waltereit R, Kautt S, Bartsch D (2008) Expression of MEGAP mRNA during embryonic development. Gene Expr Patterns 8:307-310.

Waltereit R, Leimer U, von Bohlen Und Halbach O, Panke J, Hölter SM, Garrett L, Wittig K, Schneider M, Schmitt C, Calzada-Wack J, Neff F, Becker L, Prehn C, Kutscherjawy S, Endris V, Bacon C, Fuchs H, GailusDurner V, Berger S, Schönig K, et al. (2012) Srgap $3^{-} I^{-}$mice present a neurodevelopmental disorder with schizophrenia-related intermediate phenotypes. FASEB J 26:4418-4428.

Wefelmeyer W, Puhl CJ, Burrone J (2016) Homeostatic plasticity of subcellular neuronal structures: from inputs to outputs. Trends Neurosci 39:656667.
Wilson NK, Lee Y, Long R, Hermetz K, Rudd MK, Miller R, Rapoport JL, Addington AM (2011) A novel microduplication in the neurodevelopmental gene SRGAP3 that segregates with psychotic illness in the family of a COS proband. Case Rep Genet 2011:585893.

Wong K, Ren XR, Huang YZ, Xie Y, Liu G, Saito H, Tang H, Wen L, BradyKalnay SM, Mei L, Wu JY, Xiong WC, Rao Y (2001) Signal transduction in neuronal migration: roles of GTPase activating proteins and the small GTPase Cdc42 in the Slit-Robo pathway. Cell 107:209-221.

Woo AK (2010) Depression and anxiety in pain. Rev Pain 4:8-12.

Woolf CJ, Walters ET (1991) Common patterns of plasticity contributing to nociceptive sensitization in mammals and Aplysia. Trends Neurosci 14:74-78.

Wuertenberger S, Groemping Y (2015) A single PXXP motif in the C-terminal region of srGAP3 mediates binding to multiple SH3 domains. FEBS Lett 589:1156-1163.

Yang G, Lai CS, Cichon J, Ma L, Li W, Gan WB (2014) Sleep promotes branch-specific formation of dendritic spines after learning. Science 344:1173-1178.

Yang Y, Zhou Q (2009) Spine modifications associated with long-term potentiation. The Neuroscientist 5:464-476.

Yang Y, Marcello M, Endris V, Saffrich R, Fischer R, Trendelenburg MF, Sprengel R, Rappold G (2006) MEGAP impedes cell migration via regulating actin and microtubule dynamics and focal complex formation. Exp Cell Res 312:2379-2393.

Yao Q, Jin WL, Wang Y, Ju G (2008) Regulated shuttling of Slit-RoboGTPase activating proteins between nucleus and cytoplasm during brain development. Cell Mol Neurobiol 28:205-221.

Takumi T, Ramírez-León V, Laake P, Rinvik E, Ottersen OP (1999) Different modes of expression of AMPA and NMDA receptors in hippocampal synapses. Nat Neurosci 2:618-624.

Zhang QP, Zhang HY, Zhang XF, Zhao JH, Ma ZJ, Zhao D, Yi XN (2014) srGAP3 promotes neurite outgrowth of dorsal root ganglion neurons by inactivating RAC1. Asian Pac J Trop Med 7:630-638.

Zhao P, Hill M, Liu S, Chen L, Bangalore L, Waxman SG, Tan AM (2016) Dendritic spine remodeling following early and late Racl inhibition after spinal cord injury: evidence for a pain biomarker. J Neurophysiol 115:2893-2910.

Zuo Y, Lin A, Chang P, Gan WB (2005) Development of long-term dendritic spine stability in diverse regions of cerebral cortex. Neuron 46:181-189. 